\title{
Debatendo religiosidades com os estudantes da EJA/Fpolis
}

\author{
Anna Karla Vieira Martins* \\ Joana Vieira Borges** \\ Osmar José Nenevêt**
}

\begin{abstract}
Resumo: Este artigo trata de um relato de experiência de estágio com o tema "religiosidades" na Educação de Jovens e Adultos do município de Florianópolis, Santa Catarina. O objetivo é discutir as possibilidades e as dificuldades de trabalhar com esse tema na escola, especialmente na Educação de Jovens e Adultos, garantindo, ao mesmo tempo, o fortalecimento do princípio de laicidade do Estado brasileiro. Metodologicamente, optamos em desenvolver uma intervenção na EJA (oficina) sobre religiosidade a partir de uma proposta de construção de conceitos, amparada por discussões realizadas na área de ensino de História. Consideramos a importância e a necessidade desse debate, uma vez que vivemos em uma sociedade multicultural onde as religiosidades, apesar de ocuparem um espaço de destaque, são pouco debatidas no ambiente escolar. Apesar das dificuldades que vivenciamos, acreditamos que a nossa experiência foi extremamente válida diante dos acontecimentos contemporâneos de violência e intolerância que ocorrem todos os dias no Brasil e no mundo.
\end{abstract}

Palavra-chaves: ensino de história, educação de jovens e adultos, religiosidades.

Debatendo religiosidades con los estudiantes de EJA / Fpolis.

Resumen: Este artículo trata de un relato de experiencia de práctica docente con el tema "religiosidades" en la Educación de Jóvenes y Adultos del municipio de Florianópolis, Santa Catarina. El objetivo es discutir las posibilidades y las dificultades de trabajar con ese tema en la escuela, especialmente en la Educación de Jóvenes y Adultos, garantizando, al mismo tiempo, el fortalecimiento del principio de laicidad del Estado brasileño. Metodológicamente, optamos en desarrollar una intervención en la EJA (taller) sobre religiosidad a partir de una propuesta de construcción de conceptos, amparada por discusiones realizadas en el área de enseñanza de Historia. Consideramos la importancia y la necesidad de este debate, ya que vivimos en una sociedad multicultural donde las religiosidades, aunque ocupen un espacio de destaque, son poco debatidas en el ambiente escolar. A pesar de las dificultades que vivimos, creemos que nuestra experiencia ha sido extremadamente válida ante los acontecimientos contemporáneos de violencia e intolerancia que ocurren todos los días en Brasil y en el mundo.

Palabras-clave: enseñanza de la história, educación de jóvenes y adultos, religiosidades.

\section{Introdução}

O ano de 1891 configura na história do Brasil não apenas como a data de criação da Constituição, mas também da separação entre Estado e Igreja sob a perspectiva da laicidade. Ou seja, um Estado que professa a liberdade frente a qualquer manifestação

\footnotetext{
Graduada no Curso de Bacharelado e Licenciatura em História da Universidade Federal de Santa Catarina. E-mail: annakvmartins@ outlook.com.

** Doutora em História, professora do Departamento de Metodologia de Ensino da Universidade Federal de Santa Catarina. E-mail: joana.borges@ufsc.br.

*** Graduando no Curso de Bacharelado e Licenciatura em História da Universidade Federal de Santa Catarina. E-mail: osmarcabelo@ hotmail.com.
} 
religiosa ou ausência dela, garantindo o direito à liberdade individual de escolha do sujeito. Atualmente, tal prerrogativa está presente no Art. 19, I da Constituição de 1988 e mesmo passados 28 anos, desperta muitas discussões.

Durante um ano acompanhamos as atividades desenvolvidas em um dos núcleos da Educação de Jovens e Adultos (EJA) no município de Florianópolis com o intuito de analisar os debates em torno da laicidade do Estado e a conceituação das religiosidades. ${ }^{1}$ Nesse ínterim, percebemos as particularidades da EJA em Florianópolis, que tem por princípio educativo ensinar pela realização de pesquisas produzidas pelos estudantes, de acordo com seus próprios interesses. Essa perspectiva valoriza a leitura e a escrita, colocando o aluno como agente do seu conhecimento, e os professores com o papel de orientar na realização do trabalho investigativo (Cf. SMF/DEJA, 2012).

Quando nos deparamos com tal particularidade ficamos cada vez mais sujeitos às construções de relações que envolvem aluno e professor onde, de acordo com Monteiro (2003, p. 10), "surgem múltiplas possibilidades de apropriação e interpretação", principalmente quando possuímos as mais diversas visões sobre o mundo. Esses olhares só são possíveis graças à forma dialógica de ensino que aproxima alunos e professores através de suas pesquisas.

Nesse cenário, nossa maior dificuldade e desafio foram os preconceitos construídos pelos alunos acerca das religiões. Manter um diálogo com eles e elas a respeito dessa temática foi por diversas vezes um tabu. Contudo, nós, como professores, temos que tomar cuidado para não defender as nossas convicções pessoais, como nos diz a historiadora Eliane Moura da Silva:

É muito importante lembrar ao professor que o tema religião desperta paixões variadas em sala. Deve existir uma sensibilização com a classe para fazer uma distinção entre aula de catequese e um estudo sobre religiões. O professor deve dizer com clareza que para o historiador não existe uma religião mais correta do que a outra. As questões devem evitar a apologética e tentar um estudo histórico efetivo. É sempre importante frisar que há locais em que, em nome de uma concepção de Deus, as pessoas matam os adversários de uma outra concepção. Assim, o estudo comparativo acaba sendo um exercício fundamental de tolerância e de convivência de culturas

\footnotetext{
A professora Joana Vieira Borges, do Departamento de Metodologia de Ensino (MEN) da UFSC, orientou o estágio mencionado durante o segundo semestre de 2015, no qual a experiência descrita foi realizada, e o primeiro semestre de 2016, momento da primeira versão deste texto. No núcleo de estágio, tivemos a supervisão da professora-coordenadora Rosemar Ucha Peres e da equipe de professores.
} 
diversas. Como o professor também possui uma convicção pessoal (seja um católico, um evangélico, um ateu ou outra) ele deve, igualmente, perguntar se sua visão das outras religiões não é estereotipada e preconceituosa (SILVA, 2005, p. 213).

Por isso a primeira pergunta que nos fizemos foi: Como trabalhar o tema "religiosidades" em sala de aula em uma instituição pública sem adotar discursos proselitistas, abstendo-nos de crenças e/ou opiniões pessoais? Como manter o respeito às crenças e opiniões, observando e respeitando as leis constitucionais que garantem a laicidade do Estado brasileiro? Dessa forma, queremos discutir e apresentar nossa experiência como docentes na inserção e abordagem do tema "religiosidade" dentro do cenário e das particularidades da educação de jovens e adultos em Florianópolis.

Emergiram então, a partir dessas percepções iniciais, a necessidade de buscar na história e na didática uma forma de conceituar e agir em sala de aula, de expandir o horizonte desses alunos acerca da diversidade religiosa e do caráter laico do Estado. Nesse sentido, optamos metodologicamente pela construção de conceitos historicos, dialogando então com as obras desenvolvidas por Ana Maria Monteiro (2003), Marlene Cainelli e Maria Auxiliadora Schimidt (2004), autoras que apresentam, em algumas de suas produções escritas, experiências e pesquisas sobre a construção de conceitos no ensino de história. Com base nas duas últimas autoras, buscamos organizar nosso trabalho refletindo acerca de tais premissas.

\footnotetext{
O trabalho com a construção de conceito no ensino da História implica, pelo menos, valorizarem-se duas questões. A primeira é o respeito pelo conhecimento do aluno, o conjunto de representações que ele já construiu acerca do mundo em que vive e que traz para a sala de aula. (...) A segunda questão, ligada à primeira, implica que, com base em suas representações, o aluno tem a possibilidade de efetivar suas próprias ideias sobre os fenômenos e objetos do mundo social, em vez de ser mero receptor passivo das informações no professor (SCHMIDT; CAINELLI, 2004, p.61-62).
}

Trabalhar com construção de conceitos, como demonstrado nesse artigo, foi fundamental em diversos aspectos, sobretudo porque contribuiu com a proposta da EJA/Florianópolis, uma vez que também previa a importância de considerarmos os saberes dos estudantes e suas vivências, reiterando a concepção de que aprendemos professores e estudantes - por toda a vida e em diferentes espaços. Segundo Schmidt e Cainelli (2004), as representações dos estudantes são o "ponto de partida" do trabalho com a construção de conceitos históricos, e cabe ao professor, mediador do processo de 
aprendizagem, expandir crticamente as possibilidades de conhecimento em relação a esses saberes prévios de modo que os estudantes consigam construir novas categorias explicativas da realidade social em discussão.

Utilizamos como fontes para a nossa discussão as atividades realizadas pelos alunos e os nossos diários de campo, com relatos de nossa experiência desde o acompanhamento, observação e orientação das pesquisas produzidas pelos alunos, bem como das demais atividades realizadas no núcleo, como, por exemplo, a realização da nossa oficina. Também consideramos o projeto de ensino e o plano de oficina elaborados por nós durante o estágio.

Ainda que grande parte da população brasileira frequente cultos religiosos de algum credo, e a maioria considere a religião como algo importante, Eliane Moura da Silva assevera que

\footnotetext{
As religiões raramente aparecem como objetivo específico de estudo, sobretudo nos textos para o ensino básico. (...). Como vivemos em uma sociedade laica, com total separação entre religião e estado, o que garante a liberdade de opção religiosa, talvez não avaliemos devidamente a sua importância cultural e política dessa separação (SILVA, 2005, p. 206).
}

Nesse sentido, nossa intervenção no núcleo foi pensada de modo a auxiliar os alunos a desenvolverem suas pesquisas sobre temas que se articulassem com o conceito de religiosidade, sem que eles se desviassem, necessariamente, de suas próprias crenças e opiniões pessoais, mas que percebessem a importância de questionar e investigar, de maneira crítica, as hipóteses levantadas e de acolher as convicções e crenças de seus colegas, garantindo, dessa forma, o fortalecimento dos princípios do Estado laico expressos na Constituição. Consideramos também a importância de discutir o assunto, afinal, vivemos em uma sociedade multicultural onde as religiosidades, apesar de ocuparem um espaço de destaque, são pouco debatidas no ambiente escolar.

\section{Discutir ou não discutir religiosidades na sala?}

O ensino de história no Brasil adotou, entre outros objetivos, o de ser uma ferramenta de inclusão das diferentes culturas e etnias que formam o nosso povo. Segundo o capítulo II, seção I, artigo 26, parágrafo $4^{\circ}$ da Lei de Diretrizes e Bases da Educação Nacional (LDB), Lei 9.394/96, promulgada pelo então presidente da 
república Fernando Henrique Cardoso: “O ensino da História do Brasil levará em conta as contribuições das diferentes culturas e etnias para a formação do povo brasileiro, especialmente das matrizes indígena, africana e europeia" (BRASIL, 1996). Mais recentemente, duas leis alteraram a LDB: a Lei 10.639/2003 e 11.645/2008, que instituiram a obrigatoriedade da temática da História da Cultura afro-brasileira e indígena na educação nacional. A partir desse panorama inclusivo é interessante pensar que a EJA Florianópolis está um passo à frente justamente por incentivar ao aluno que compartilhe com os demais as suas experiências e saberes, possibilitando assim diversas vezes a inclusão das mais variadas temáticas sócio-culturais da população brasileira, contemplando as questões étnico-raciais e religiosas ${ }^{2}$. Assim como Tiago Duque (2014), acreditamos que a religião é elemento constitutivo de tantas outras dimensões da cultura e está em constante diálogo com as deliberações políticas e as práticas educacionais, logo, apresenta-se para além das aulas de Ensino Religioso, que muitas vezes naturalizam certas visões em detrimento de outras.

Em um dos encontros no núcleo da EJA Florianópolis, mediante uma discussão acerca das pesquisas, notamos que quando o assunto era religião os alunos carregavam consigo uma percepção homogeneizante. Essa representação é abordada por Eliane Moura da Silva, ao afirmar que, por sermos formados em um berço ocidental, o termo religião parece vir automaticamente ligado a uma tradição cristã, excludente de toda e/ou qualquer outra forma de representação religiosa.

Antes de prosseguirmos, devemos, no entanto, fazer a separação dos termos em questão: religião e religiosidade. Para Eliane Silva, religião se refere a "apenas um conjunto de regras, observâncias, advertências e interdições, sem fazer referência a divindades" (SILVA, 2005, p.207), enquanto para Carlos Roberto Jamil Cury A etimologia do termo religião, donde procede o termo religioso, pode nos
dar uma primeira aproximação do seu significado. Religião vem do verbo
latino religare (re-ligare). Religar tanto pode ser um novo liame entre um
sujeito e um objeto, um sujeito e outro sujeito, como também entre um objeto
e outro objeto. Obviamente, o religar supõe ou um momento originário sem a
dualidade sujeito/objeto ou um elo primário (ligar) que, uma vez desfeito,
admite uma nova ligação (re-ligar). (CURY, 2004, p. 187)

2 Essa característica pode ser notada claramente nos objetivos do curso, definidos pelas "Diretrizes para a implantação do plano da Educação de Jovens e Adultos da rede Municipal de Ensino de Florianópolis", ao afirmar, mais especificamente no quinto item, que o aluno deve: "compreender e atuar de forma crítica, participativa e dialógica na realidade social” (SME/DEJA, 2012, p. 3). 
Tais afirmações seriam suficientes para gerar uma discussão demorada em sala de aula, uma vez que apresentam conceituações mais complexas do que aquelas trazidas pelos estudantes e que mobilizam um senso comum. Já o termo religiosidade pode ser descrito como uma forma individual e particular do sujeito experimentar uma determinada religião (SILVA, 2005). Ou seja, uma religião carrega consigo determinadas regras, mas a forma com que o sujeito vive essa experiência determina a sua religiosidade.

Incorporado a isso surge a polêmica da inserção histórica do ensino religioso em escolas públicas no Brasil, geralmente voltado para uma doutrinação cristã, ferindo assim as leis constitucionais que garantem a laicidade do estado. Muitos teóricos defendem a exclusão da disciplina de Ensino Religioso, justamente por não crerem na sua capacidade de abranger caráter facultativo determinado pela Constituição ${ }^{3}$. É o caso de Carlos Roberto Jamil Cury, que defende que

O caráter facultativo de qualquer coisa implica o livre-arbítrio da pessoa responsável por realizar ou deixar de realizar algo que se lhe é proposto. A faculdade implica, pois, a possibilidade de poder fazer ou não, de agir ou não como algo inerente ao direito subjetivo da pessoa. Ora, para que o caráter facultativo seja efetivo e a possibilidade de escolha se exerça como tal, é necessário que, dentro de um espaço regrado como o é o das instituições escolares, haja a oportunidade de opção entre o ensino religioso e outra atividade pedagógica igualmente significativa para tantos quantos que não fizerem a escolha pelo primeiro. (CURRY, 2004, p. 189)

Segundo Ana Maria Cavaliere, após observar e realizar uma pesquisa empírica sobre a experiência do ensino religioso implantado no ano de 2000, no Rio de Janeiro:

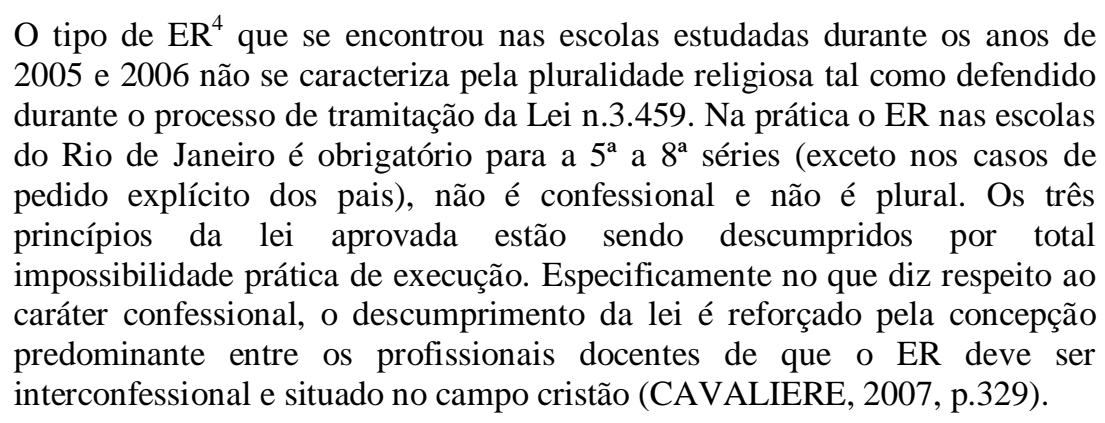

3 Torna-se obrigatório mediante Lei Nacional que sejam vedados: "cultos religiosos ou igrejas, subvencioná-los, embaraçar-lhes o funcionamento ou manter com eles ou seus representantes relações de dependência ou aliança (...)" (BRASIL, 1988).

$4 \quad$ Ensino Religioso. 
Devemos assim diferenciar esse tipo de ensino religioso que vem sendo aplicado durante décadas no Brasil, com o ensino de religiosidade do qual defendemos e consideramos como fundamental para a aprendizagem de "posturas não etnocêntricas", bem como "a garantia de espaços mais democráticos e valorativos da diferença cultural religiosa no contexto escolar" (DUQUE, 2014, p. 62-64). Seria um erro obviamente crer que com o estabelecimento da legislação os preconceitos e problemas desapareceriam automaticamente. Por esse motivo é necessário, juntamente com a sociedade, a construção de espaços educativos de discussão que consigam respaldar a laicidade do Estado brasileiro.

Para começar a fazer valer todas estas determinações constitucionais devemos analisar antes a situação do professor. O educador antes de se inserir em sala de aula deve se perguntar "se a sua visão das outras religiões não é" também "estereotipada ou preconceituosa" (SILVA, 2005, p. 213), praticando assim o exercício "de se colocar no lugar do outro" enquanto um estranhamento cultural de perceber outro e "compreendêlo sob suas próprias lógicas" (DUQUE, 2014, p.61-62). Antecipadamente o professor deve desprender-se do etnocentrismo e criar uma esfera que permita compreender as diferenças, ponderar acerca das críticas aos costumes dos "outros", e assim ser capaz de rever suas próprias práticas e visões de mundo.

Ao realizarmos esta reflexão inicial, antes mesmo de adentrar em sala de aula, aumentaremos as possibilidades de pensar estratégias de aprendizagem que tenham por objetivo discutir o tema religiosidade, quebrando preconceitos e nos aproximando da diversidade cultural através do conhecimento. Para que isso seja efetivo no ambiente escolar, devemos abordar os fenômenos religiosos como parte integrante das culturas, como afirma Marielle de Souza Vianna, e, portanto, valorizados como patrimônio cultural e histórico da humanidade. Segundo a autora:

Para viver democraticamente em uma sociedade multicultural é preciso conhecer e respeitar as diferentes culturas que a constituem. E o ambiente escolar é o espaço privilegiado para promover o conhecimento e a valorização da trajetória dos diferentes grupos sociais, pois só assim será possível superar atitudes de intolerância em relação às diferenças culturais (VIANNA, 2011, p. 10). 


\section{A construção de conceitos no ensino de História e na oficina na EJA}

Podemos considerar alguns conceitos como universais, uma vez que perpassam diferentes contextos históricos. Se partirmos do exemplo do conceito de religião, veremos que cada sociedade o adequou conforme sua conveniência ao longo da história. Dentro do campo historiográfico, conceitos constituem uma importante área de estudo, e quando pensamos em sua aplicabilidade para a realidade escolar devemos ter em mente que os mesmos nos ajudam a "conhecer, discutir, narrar e refletir" acerca de algo (VIANNA, 2011, p.3).

Para melhor delimitar esta ideia recorremos a Koselleck, quando o mesmo afirma: "Sob um conceito estão subsumidos a multiplicidade da experiência histórica e um conjunto de relações teóricas e práticas que, enquanto tal, não é dado nem é objeto de experiência a não ser por esse conceito" (apud MONTEIRO, 2003, p. 24). Ou ainda, como descrito na obra de Maria Auxiliadora Schmidt e Marlene Cainelli (2014), que a construção de conceitos nos permite controlar de forma ordenada e cientificamente elementos da realidade social, principalmente no que se refere ao reconhecimento de possibilidades de interpretação. De acordo com as autoras "os conceitos podem ser considerados possibilidades cognitivas que os indivíduos têm na memória disponíveis para os arranjos que mobilizem, de forma conveniente, suas capacidades informativas e combinatórias" (SCHMIDT; CAINELLI, 2009, p.84). Mas, como então podemos trabalhar essas questões em sala de aula? Como mobilizá-los na proposta e prática educativa vigente na EJA em Florianópolis?

Primeiro, devemos ser conscientes e capazes de utilizar os conhecimentos prévios dos alunos e por isso, como já dito antes, dentro de nossas observações, a EJA Florianópolis sai na frente ao proporcionar ao aluno a elevação de experiências que cercam a sua vida em diferentes momentos do processo de aprendizagem proposto pelo princípio de "educar pela pesquisa". Segundo, devemos ser capazes de avaliar os alunos como dotados de uma representação própria de vida, e não meros receptores de informação. Deparamo-nos na sala de aula com diferentes opiniões formadas sobre as religiões, e saber mediar e problematizar os diferentes entendimentos dos fenômenos religiosos a partir da ideia de laicidade do Estado foi fundamental. Terceiro, e para a análise do professor, devemos ser conscientes que: 
Os conceitos em História raramente são usados em sua forma absoluta. Geralmente eles são complementados por adjetivos que procuram explicitar a situação a que se referem. O sentido mais preciso é explicitado pelo adjetivo que ele recebe e o "jogo" comparativo implica também em buscar o adjetivo pertinente (MONTEIRO, 2003, p.26).

O conceito de religião normalmente vem seguido de adjetivos como: cristã, de matriz africana, árabe, indígena, entre outras, o que possibilita uma interligação de vários fatos em um só, ou até mesmo do trabalho com uma história por eixos que permitam a incorporação de novos conhecimentos pertinentes a outras áreas, que não somente a história.

Em seu texto sobre a importância dos conceitos, Maria Auxiliadora Schmidt nos apresentou um modelo que auxilia na seleção de alguns princípios que devem ser tratados em sala de aula (SCHMIDT, 2009). O foco de sua atenção são as escolas de ensino básico, maspodemos tomar algumas de suas sugestões para pensar a proposta da EJA, como, por exemplo, a escolha ampla de conceitos que estejam presentes na realidade do aluno, a sua universalidade e possibilidade de ser aplicado a mais de um determinado assunto, a simplificação para facilitação da aprendizagem do aluno, entre outros (Cf. PMF/SME, 2008).

Quanto à discussão sobre a importância ou finalidade da construção de conceitos no ensino de história em sala de aula, não encontramos divergências, o que muda são as formas de trabalhar tal face do campo histórico. É possível notar que em sua maioria os autores dessa área partem da ideia de que todo trabalho historicizado em sala de aula deve iniciar no estudo e construção dos conceitos que o envolvem. Só assim o aluno conseguirá ter a compreensão e assimilação que se fazem necessárias (MONTEIRO, 2003, p.20).

Desse modo, quando pensamos em trabalhar religião/religiosidades em sala de aula, a construção de conceitos apresenta-se como uma metodologia de ensino válida ao possibilitar atividades de definição e compreensão, relacionando os significados amplos e restritos dos conceitos, bem como as contextualizações necessárias.

\section{Uma proposta de discussãosobre religiosidades na EJA/Florianópolis}

Partindo dos pressupostos explícitos anteriormente, permanece latente a necessidade de elaborar projetos educativos que abordem a temática religiosidade nas 
escolas de um ponto de vista didático, inclusivo e interativo, e que, acima de tudo, consigam abranger suas originalidades, formas de mobilização e situação em tempo e espaço, visando propagar a tolerância como sendo "fundamental para o respeito entre pessoas e memória histórica" (SILVA, 2004, p.206).

Como já mencionado, durante um ano acompanhamos o cotidiano escolar de um dos núcleos da Educação de Jovens e Adultos em Florianópolis, junto a estudantes que buscavam concluir a segunda etapa do Ensino Fundamental ( $5^{\circ}$ ao $9^{\circ}$ ano). Por meio desta experiência tivemos contato com um público diverso que, em sua maioria, eram jovens que não conseguiram concluir a escolarização no tempo "certo"5 e/ou adultos que em algum momento tiveram que abandonar os estudos, geralmente pela necessidade de trabalho ou por uma gravidez precoce.

Muitos desses alunos, em algum momento, já foram vistos como indesejados em outras instituições de ensino, tomados como "adolescentes problemas", características ainda eram latentes naquele espaço. O universo deles girava em torno, muitas vezes, de drogas e problemas familiares dos mais variados e, em alguns casos, percebíamos que o espaço escolar era um meio de escapar dessas tensões do dia a dia.

Era no núcleo da EJA que os alunos estabeleciam contato com professores de diversas áreas, uma vez que a metodologia de ensino se dava através da elaboração das pesquisas e a realização de oficinas com o propósito de debater alguma problemática em destaque tanto nas investigações quanto no cotidiano escolar. As oficinas ocorriam geralmente às sextas-feiras, e enfatizavam ainda questões em que se percebia alguma defasagem nos processos de pesquisa. É importante frisar que em alguns casos partia dos alunos o pedido para um estudo específico. Em sala de aula, contavam com o auxílio e orientação dos professores e estagiários do curso de História para desenvolverem suas investigações e, posteriormente, elaborarem a socilização dos resultados encontrados.

O método que os alunos da EJA Florianópolis utilizam para começarem as suas pesquisas, após a escolha do tema, consiste, primeiramente, em criar um mapa

Por "tempo certo" compreendemos o espaço de tempo determinado pelas diretrizes nacionais, que determinam como 15 anos a idade regular para conclusão do Ensino Fundamental. Relativizamos aqui a ideia de que a aprendizagem se dá conforme tempos determinados e apenas no contexto escolar.

6 Ver, a esse respeito, CAMPOS, Marli Aparecida Silva; MARTURANO, Edna Maria. Competência Interpessoal, problemas escolares e a transição da meninice à adolescência. Paidéia, Ribeirão Preto, v. 25, n. 13, p.73-84, maio 2003. Disponivel em: 〈http:/www.revistas.usp.br/paideia/article/viewFile/46678/50434>. Acesso em: 01 maio 2016. 
conceitual, que reúne todas as problemáticas a serem respondidas durante a pesquisa, bem como a organização de toda a sua estrutura. Para criar um espaço de interação entre os alunos, fazia-se a explanação desses mapas para toda a turma com o intuito de incentivar a participação na pesquisa dos demais colegas, abrindo um espaço para ajuda e sugestões. Foi durante uma dessas explanações de mapas conceituais que apareceu pela primeira vez para nós a necessidade que os alunos tinham em ter uma abordagem histórica sobre o tema religiosidade, sobretudo um debate considerando o caráter laico do Estado brasileiro.

Uma aluna escolheu como temática de pesquisa a umbanda. Ao acompanharmos este caso, percebemos a dificuldade que ela teve para pesquisar sobre o tema, desde a escolha das fontes, que muitas vezes só endossavam o preconceito ${ }^{7}$, como também a necessidade de refletir a respeito do assunto pensando outras questões para além daquelas já preconcebidas. Da mesma forma, vimos como alguns alunos carregavam preconceitos com relação às religiões de matriz africana, percebendo-as como "estranhas" e desligadas de suas realidades ${ }^{8}$.

Além do caso mencionado acima, durante uma apresentação de pesquisa sobre mitologia percebemos alguns comentários de rejeição ao tema vindo de um pequeno grupo de alunos cristãos, que refutaram aquela demonstração de religião por lhes parecer excêntrica e atemporal, mostrando assim uma forma de intolerância religiosa por falta de conhecimento.

Sendo assim, iniciamos a elaboração do projeto de ensino e o planejamento de nossa intervenção (oficina) realizando um levantamento bibliográfico e, posteriormente, as leituras, que conseguissem de alguma forma nos amparar no debate ao qual estávamos propondo frente ao diagnóstico percebido no núcleo da EJA. Para tanto, partimos das seguintes temáticas: religião/religiosidade e suas construções históricas dentro da realidade brasileira, bem como Estado Laico $^{9}$ e liberdade de expressão.

7 A maioria das pesquisas dos alunos da EJA Florianópolis são feitas pela Internet e uma apresentam grande quantidade de materiais, com conteúdos e objetivos diversos. No caso em específico, a aluna encontrou durante a sua pesquisa, em sua maioria, fontes de sites cristãos, os quais tinham uma visão negativa e estereotipada da umbanda.

8 Fator que de acordo com Eliane Moura da Silva pode ser explicado pela construção ocidental do termo "religião", estreitamente ligado à tradição cristã (SILVA, 2005, p.207).

9 Para abordar esta perspectiva, recomendamos a leitura do texto de Débora Diniz, apresentado no X Seminário LGBT do Congresso Nacional, intitulado Dez palavras sobre laicidade. Disponível em: <http://www.acaoeducativa.org.br/fdh/wpcontent/uploads/2015/12/Dez_palavras_sobre_laicidade_Diniz.pdf>. Acesso em: 20 ago. 2015. 
Autores como Leandro Karnal (2014), Thiago Duque (2014) e Eliane Silva (2005) nos ajudaram a pensar uma proposta de discussão das religiosidades na escola que considerasse ainda nossas reflexões sobre o ensino de história. Além disso, recorremos também à Maria Auxiliadora Schmidt, Marlene Cainelli (2009) e Ana Maria Monteiro (2003) no intuito de compreendermos como trabalhar a construção de conceitos históricos em sala de aula. Terminada a experiência do estágio, consideramos que modificaríamos muitos elementos da aula/oficina. No entanto, cabe-nos no presente momento descrever e analisar a sequência didática que adotamos no sentido de socializarmos a nossa proposta de discussão da religião/religiosidades na EJA Florianópolis.

Primeiramente, logo após as leituras, perguntamo-nos enquanto dupla de estágio: O que gostaríamos que os alunos aprendessem com nosso projeto? Em segundo, como faríamos para trabalhar os aspectos mencionados neste artigo de forma clara e simples (ainda que problematizadora) ${ }^{10}$, e que nuances daríamos ao tema?

Inicialmente, esperávamos que eles compreendessem que a nossa constituição nacional era diversa: somos descendentes de portugueses, africanos, indígenas e de muitas outras etnias e culturas. Para isso, contamos com o auxílio de um mapa-múndi, mostrando de quais regiões do mundo vieram os povos que deram origem a nossa nação.

$\mathrm{Na}$ segunda etapa, de modo dialógico, iniciamos a construção do conceito de religião, interrogando-os a respeito e atentando para as diversas representações e conhecimentos expressados nas respostas dadas. Nossa intenção era partir dos conhecimentos prévios dos alunos para trazer elementos mais complexos para o conceito. Intencionávamos fazer com que a turma percebesse que a nossa realidade religiosa brasileira atual, bem como as denominações e práticas decorrentes da pluralidade de concepções, trazia as marcas da multiculturalidade que nos forma enquanto sociedade.

Também apresentamos alguns aspectos em relação ao sincretismo religioso no cenário nacional por meio de algumas imagens artísticas projetadas com auxílio do

10 Uma das orientações que recebemos, dos próprios professores da instituição, antes mesmo de começarmos a acompanhar as atividades no núcleo, foi que deveríamos suspeitar da compreensão do que nos parece "óbvio". Estamos habituados a utilizar termos que não são corriqueiros na maioria da realidade daqueles alunos, e por isso havia a necessidade de abordar a temática de uma forma simples. 
projetor. Por conta da vastidão de fenômenos religiosos das mais diversas religiões, focamos nas religiões que percebemos durante a investigação a respeito do cotidiano e cultura escolar como mais presentes em suas vidas e em seus interesses de pesquisa: a umbanda e o catolicismo. A forma mais didática para este momento foi a utilização da pintura como uma fonte histórica plausível de análise, favorecendo assim a percepção de elementos recorrentes como, por exemplo, o sincretismo entre Iemanjá e Nossa Senhora dos Navegantes, o Diabo e Exú, e assim por diante.

Havíamos planejado esta parte introdutória da oficina - mais expositiva e dialogada - para a primeira parte da noite de aula. Após o intervalo, a ideia era então abordar com os alunos a construção de uma noção do que viria a ser Estado Laico, e como eles compreendiam sua garantia no dia a dia. A primeira consideração que tecemos logo após a realização da oficina foi a falta de conhecimento dos estudantes, e consequentemente de participação no debate, a respeito do conceito de laicidade estatal. Importante pontuar que o que nos auxiliou na discussão sobre Estado Laico foi a escolha por partir de um enxerto da própria Constituição ${ }^{11}$, bem como de algumas reportagens atuais para leitura e análise dessa discussão sobre a garantia da laicidade no cotidiano. Em ambos os momentos da oficina - realizada em uma sala de aula utilizamos os seguintes recursos didáticos: quadro branco, slides e projetor (sobretudo para a exibição das imagens) e uma atividade impressa em folha branca A4 entregue a cada um dos alunos.

\section{Resultados e Discussões}

Durante todo o tempo no qual pesquisamos o tema das religiosidades e elaboramos nosso projeto e demais planejamentos, deparamo-nos com muitos obstáculos; alguns já esperados, visto nossa participação prévia no núcleo e acompanhamento dos alunos durante parte do ano letivo.

Primeiramente, percebemos os desafios de elaborar uma intervenção utilizando conceitos que mobilizam crenças religiosas em um curto espaço de tempo didático. Como já mencionado, religião e religiosidade possuem conceitos complexos, por essa razão devemos ter todo o cuidado possível para evitar interpretações equivocadas,

11 Art. 19, inc. I da Constituição Federal, BRASIL, 1988. 
etnocêntricas, e que sirvam para a manutenção do proselitismo religioso na escola. Isso traz uma dificuldade ainda maior na seleção do material e das fontes das quais o docente irá utilizar. Como historiadores, esse cuidado deve ser redobrado para que as fontes não sejam trabalhadas de modo a monumentalizar algumas concepções, crenças e práticas como mais legítimas do que outras, ou ainda indiscutíveis.

Outra dificuldade que o tema nos trouxe é que ele carrega conceitos que eram até então estranhos para a grande maioria dos alunos. Durante a nossa intervenção, quando tratamos da noção de Estado Laico, nenhum aluno expressou conhecimento acerca do tema em debate. O mesmo ocorreu com os temas sincretismo e mesmo religiosidades, que exigiram um tempo maior do que o planejado para explanação e discussão.

Como já aludido, a maioria dos alunos da EJA durante a nossa experiência de estágio trazia consigo preconceitos sobre o tema, seja da religião que participam ou das demais. Por isso concordamos com Eliane Silva (2005) quando esta afirma que discutir religião/religiosidades em sala de aula possivelmente despertará uma grande gama de paixões nos alunos e, tomando nosso caso em específico, irá gerar momentos de discussões polêmicas. Um exemplo disso foi a rejeição de uma aluna a uma fala específica sobre a umbanda. De acordo com ela, essa religião era "coisa do Diabo", e o debate promovido a fez sair da sala de aula, por vontade de não mais participar.

As dificuldades de se discutir esse tema de forma democrática e abrangente na escola são um desafio, e consideramos que sejam consequência do próprio proselitismo, no caso cristão, promovido por muitos anos nas aulas de ensino religioso nas escolas públicas brasileiras. Acreditamos que as discussões mais problematizadoras sobre os temas referentes às religiosidades em seus aspectos históricos, sociais e culturais ainda seja uma novidade na escola; estranha aos estudantes e ao corpo docente também. Entretanto, é importante que os professores e alunos percebam a importância desse debate, mesmo que ele seja desafiante. Como defende Tiago Duque:

Não existe outro caminho possível para pensarmos nas transformações que nos levarão a contextos de igualdade e valorização das diferenças que não passe pela reflexão bem-orientada. Se não discutirmos religião na escola, nesta perspectiva não etnocêntrica e aberta ao relativismo, as coisas se manterão de forma desigual porque não conseguiremos pensar em ideias e ações para tornar a escola e a sociedade menos excludentes com quem tem uma fé diferente da maioria ou com quem não tem nenhuma fé (DUQUE, 2014, p. 84). 
Outro aspecto interessante foi perceber como os alunos se apropriaram da intervenção proposta, apresentando, ao final, certa dificuldade de relativizar suas crenças e descentrá-las no intuito de refletir sobre a necessidade de garantirmos o caráter laico do Estado brasileiro. Ao final da oficina, propomos a redação de um breve texto a partir do seguinte enunciado: "Escreva sobre a importância de construirmos uma sociedade que respeite a diversidade cultural e religiosa, assim como a liberdade de crença para cada indivíduo". Obtivemos respostas como, por exemplo: que a liberdade de escolha na verdade "vinha do livre arbítrio dado por Deus". Um aluno respondeu, "Acredito no Senhor e só ele pode nos tirar de onde estamos", e continuou, "no momento aqui é a terra da sobrevivência e acho que devemos só nos respeitar melhor cada qual com a sua liberdade de escolha”. Percebemos a reiteração e centralidade de suas crenças, e ao mesmo tempo, uma ideia de respeito à liberdade de escolha, que provavelmente se deu no sentido de contemplar parte do debate em sala e mais diretamente o enunciado da atividade.

Uma das senhoras de mais idade respondeu: "Eu não gosto de fanatismo religioso porque cada um tem o direito de tomar as suas decisões. Eles não podem decidir pela gente". Ao nos depararmos com o que podemos afirmar como sendo um desabafo pessoal, e aqui entendemos o "eles" como os representantes das instituições religiosas, percebemos ao menos um discurso dissonante, que trouxe um descontentamento com os extremismos e a questão do fanatismo, não abordada diretamente na oficina.

Inicialmente, sentimos em nossas investigações e leituras a falta de materiais, cursos e outras práticas educativas que capacitem os professores no Brasil para o debate acerca da diversidade cultural religiosa na escola - especialmente na EJA - a partir da perspectiva da laicidade. No entanto descobrimos, durante a elaboração do projeto de ensino, que o estado de Santa Catarina foi pioneiro em apresentar uma proposta de trabalho com ensino religioso nas escolas públicas catarinenses voltada à construção de uma cultura de respeito e reconhecimento da diversidade cultural religiosa (POZZER, 2016). Recentemente, a Secretaria de Estado da Educação de Santa Catarina distribuiu e disponibilizou materiais para serem utilizados em sala de aula e na formação continuada de professores de diferentes áreas do conhecimento sobre a diversidade religiosa e os 
direitos humanos ${ }^{12}$. Este ano a Associação dos Professores de Ensino Religioso de Santa Catarina (ASPERSC) faz 15 anos, e também divulga, por meio de seu site, eventos, textos, experiências e materiais didáticos para uma proposta dialógica e intercultural das religiosidades no âmbito escolar ${ }^{13}$. Em São José, município vizinho de Florianópolis, havia, até o ano de 2015, a oferta de um curso de ensino superior de Ciências da Religião, com habilitação em licenciatura em Ensino Religioso, no Centro Universitário Municipal de São José (USJ) ${ }^{14}$. Acreditamos que muito provavelmente alguns docentes prefiram não tratar do assunto não só pelo desconhecimento das produções disponíveis, mas também pelo desafio que o debate provoca, utilizando-se do próprio argumento do caráter laico do Estado previsto na Constituição.

Apesar de ser uma discussão de certo modo recente e polêmica, a experiência de estágio na EJA Florianópolis só reforçou em nós a sua importância. Esperamos que com o tempo os sujeitos na escola tenham um maior entendimento a respeito dos debates sobre as diferenças culturais percebidas por meio das diversas manifestações religiosas e os conceitos que deles decorrem, e passem a pensar em termos de possibilidades e não apenas de limites.

\section{Considerações Finais}

Gostaríamos de terminar este texto trazendo algumas reflexões avaliativas sobre nossa experiência. Em primeiro lugar, destacamos que o tempo para a elaboração do projeto de ensino e para o planejamento da oficina foi pouco diante de toda a bibliografia e, consequentemente, discussões que selecionamos para a nossa proposta de trabalho. Concomitante à produção da proposta, participávamos das atividades de orientação de pesquisas dos alunos da EJA. A leitura dos textos sobre a temática selecionada não cessou com a realização da oficina, mas continuou para a escrita deste artigo. Desse modo, muitas das reflexões que poderiam ter nos auxiliado na elaboração

12 Os materiais, produzidos em 2013, estão acessíveis no site da Secretaria de Estado da Educação de Santa Catarina em http://www.sed.sc.gov.br/servicos/programas-e-projetos/6611-diversidade-religiosa-e-direitos-humanos. Acesso em: 12 abr. 2018.

13 Ver, a esse respeito, o site da ASPERSC disponível em http://aspersc.blogspot.com.br. Acesso: 12 abr. 2018.

14 De acordo com o reitor da USJ 2016-2018, o professor Juarez Perfeito, o curso de Ciências da Religião foi encerrado por conta da "baixa demanda de interesse". Disponível em: https://usj.edu.br/usjlanca-consulta-publica-para-abertura-de-novos-cursos-de-graduacao-em-sao-jose/. Acesso em: 12 abr. 2018. 
e realização da intervenção junto aos alunos foram realizadas posteriormente. Ou seja, recomendamos que para um bom trabalho com a temática da diversidade cultural religiosa em sala de aula o professor se cerque dos diversos argumentos e debates já realizados sobre as principais questões em relação às religiosidades levantadas ao longo deste artigo.

Percebemos que o fato de termos trabalhado com mais de um conceito em uma única sequência didática de 4 horas/aula - no caso religião, religiosidade, laicidade e sincretismo - demonstrou-se problemático, pois não houve tempo necessário para que as reflexões propostas fossem trabalhadas em profundidade. Embora estivessem interligados, tivemos dificuldade em administrar os debates que emergiram na turma e, ao mesmo tempo, problematizar os conceitos em suas complexidades de definição e contextualização.

Após esta experiência, consideramos que é possível e urgente trabalhar o tema das diferentes culturas religiosas a partir de uma proposta educativa polifônica e intercultural nas escolas (POZZER, 2016) e, em especial, na EJA Florianópolis que tem como princípio educativo não apenas "ensinar pela pesquisa", mas, como observamos ao longo do estágio, "educar para a diversidade". Apesar das dificuldades que vivenciamos, acreditamos que a nossa experiência foi extremamente válida diante dos acontecimentos contemporâneos de violência e intolerância que ocorrem todos os dias no Brasil e no mundo.

\section{Referências}

BRASIL. Constituição (1988). Lei no 19, de 1988. Art. 19 da Constituição Federal de 1988. Disponível em: https://www.jusbrasil.com.br/topicos/10639289/artigo-19-daconstituicao-federal-de-1988. Acesso em: 30 set. 2016.

BRASIL. MINISTÉRIO DE EDUCAÇÃO E CULTURA. LDB - Lei n. 9394/06, de 20 de dezembro de 1996. Estabelece as diretrizes e bases da Educação Nacional. Brasília: MEC, 1996.

CAVALIERE, Ana Maria. O mal-estar no Ensino Religioso em escolas públicas. Cadernos de Pesquisa, Rio de Janeiro, v. 37, n. 131, p.303-332, ago. 2007. Trimestral.

CURY, Carlos Roberto Jamil. Ensino religioso na escola pública: o retorno de uma polêmica recorrente. Revista Brasileira de Educação, Belo Horizonte, v. 27, p.183-213, dez. 2004. 
DINIZ, Débora. Dezpalavras sobre laicidade. Disponívelem: <http// http:/www.acaoeducativa.org.br/fdh/wpcontent/uploads/2015/12/Dez_palavras_sobre_laicidade_Diniz.pdf. Acesso em: 20ago. 2015.

DUQUE, Tiago. Religiosidades e Educação Pública. In: MISKOLCI, Richard; LEITE JÚNIOR, Jorge (Orgs.). Diferenças na educação: outros aprendizados. São Carlos: Edufscar, 2014. p. 57-95.

KARNAL, Leandro. Religiões comparadas. São Paulo: Casa do saber, 2011. Disponível em: http://casadosaber.com.br/sp/media/mediauploader//r/e/relatorio.pdf. Acesso em: 23 set. 2015.

MONTEIRO, Ana Maria. A história ensinada: algumas configurações do saber escolar. História \& Ensino, Londrina, v. 9, p.37-62, out., 2003.

PREFEITURA DE FLORIANÓPOLIS. SECRETARIA MUNICIPAL DE EDUCAÇÃO. Estrutura, Funcionamento, Fundamentação e Prática na Educação de Jovens $e$ Adultos EJA. Florianópolis: SME, 2008 (Disponível em: http://www.pmf.sc.gov.br/arquivos/arquivos/pdf/22_02_2010_9.36.57.04162e08d6cd88 76612adc5ada375bd5.pdf . Acesso em: 05 abr. 2017.

POZZER, Adecir. Ensino religioso na proposta curricular de Santa Catarina/Brasil: a construção de espaços polifônicos e interculturais. In: CATARINO, Fernando; JUNQUEIRA, Sérgio Azevedo (Orgs.). $1^{o}$. Fórum Internacional de Ensino Religioso. Desafios do Ensino Religioso numa sociedade laicizada. Lisboa: Edições Universitárias Lusófonas, 2016. Disponível em: https://ipfer.com.br/wpcontent/uploads/2017/09/LIVRO-FIER.pdf . Acesso em: 12 abr. 2018.

SCHMIDT, Maria Auxiliadora; CAINELLI, Marlene. Construção do conceito histórico. In: . Ensinar História. 2.ed. São Paulo: Scipione, 2009, p. 83-96.

SECRETARIA DO ESTADO DE EDUCAÇÃO DE SANTA CATARINA. Diversidade Religiosa e Direitos Humanos (Materiais didáticos). Disponível em: Secretaria de Estado da Educação de Santa Catarina em http://www.sed.sc.gov.br/servicos/programas-eprojetos/6611-diversidade-religiosa-e-direitos-humanos. Acesso em: 12 abr. 2018.

SECRETARIA MUNICIPAL DE EDUCAÇÃO. DEPARTAMENTO DE EDUCAÇÃO DE JOVENS E ADULTOS. Diretrizes para a implantação do plano de curso da educação de jovens $e$ adultos da rede municipal de ensino de Florianópolis. Forianópolis: DEJA, 2012. Disponível em: http://www.pmf.sc.gov.br/arquivos/arquivos/doc/16_02_2012_17.58.23.4c2366919c16ff6fa8c19f510fb fldbb.doc. Acesso em: 05 abr. 2017.

SILVA, Eliane Moura da. Religião, Diversidade e Valores Culturais: conceitos teóricos e a educação para a Cidadania. Revista de Estudos da Religião, São Paulo, v. 2, p. 1-14, nov. 2004. Disponível em: http://www.pucsp.br/rever/rv2_2004/p_silva.pdf. Acesso em: 24 set. 2015.

Estudos de religião para um novo milênio. In: KARNAL, Leandro. História na sala de aula: conceitos, práticas e propostas. 6. ed. São Paulo: Contexto, 2005. 
VIANNA, Marielle de Souza. Diversidade religiosa no contexto escolar. Revista da Católica, vol. 3, n. 5, p. 01-10, jan.-jul. 2011. Disponível em: http://catolicaonline.com.br/revistadacatolica2/artigosv3n5/artigo01.pdf. Acesso em: 20 set. 2015.

Recebido em: 27 abr. 2018.

Aceito em: 28 maio 2018. 